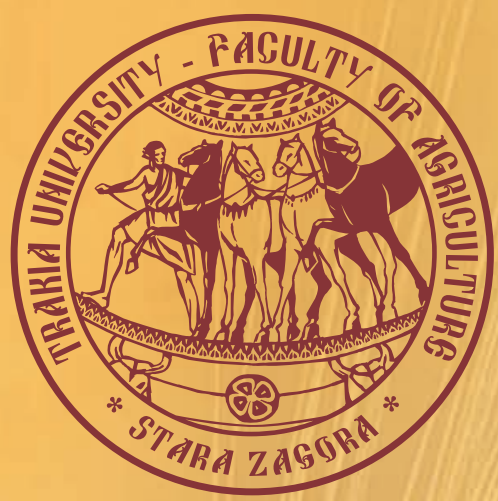

ISSN $1313-8820$ (print)

ISSN $1314-412 X$ (online)

Volume 8 , Number 4

December 2016

\title{
AGRICULTURAL
}

\section{SCIENCE AND TECHNOLOGY}

\section{6}

An International Journal Published by Faculty of Agriculture, Trakia University, Stara Zagora, Bulgaria 


\section{Editor-in-Chief}

Georgi Petkov

Faculty of Agriculture

Trakia University, Stara Zagora

Bulgaria

\section{Co-Editor-in-Chief}

Dimitar Panayotov

Faculty of Agriculture

Trakia University, Stara Zagora

Bulgaria

\section{Editors and Sections}

\section{Genetics and Breeding}

Tsanko Yablanski (Bulgaria)

Atanas Atanasov (Bulgaria)

Nikolay Tsenov (Bulgaria)

Max Rothschild (USA)

Ihsan Soysal (Turkey)

Horia Grosu (Romania)

Bojin Bojinov (Bulgaria)

Stoicho Metodiev (Bulgaria)

Svetlana Georgieva (Bulgaria)

\section{Nutrition and Physiology}

Nikolai Todorov (Bulgaria)

Peter Surai (UK)

Zervas Georgios (Greece)

Ivan Varlyakov (Bulgaria)

\section{Production Systems}

Radoslav Slavov (Bulgaria)

Dimitar Pavlov (Bulgaria)

Bogdan Szostak (Poland)

Banko Banev (Bulgaria)

Georgy Zhelyazkov (Bulgaria)

\section{Agriculture and Environment}

Ramesh Kanwar (USA)

Martin Banov (Bulgaria)

Peter Cornish (Australia)

\section{Product Quality and Safety}

Marin Kabakchiev (Bulgaria)

Stefan Denev (Bulgaria)

Vasil Atanasov (Bulgaria)

Roumiana Tsenkova (Japan)

\section{English Editor}

Yanka Ivanova (Bulgaria)
Scope and policy of the journal Agricultural Science and Technology /AST/ - an International Scientific Journal of Agricultural and Technology Sciences is published in English in one volume of 4 issues per year, as a printed journal and in electronic form. The policy of the journal is to publish original papers, reviews and short communications covering the aspects of agriculture related with life sciences and modern technologies. It will offer opportunities to address the global needs relating to food and environment, health, exploit the technology to provide innovative products and sustainable development. Papers will be considered in aspects of both fundamental and applied science in the areas of Genetics and Breeding, Nutrition and Physiology, Production Systems, Agriculture and Environment and Product Quality and Safety. Other categories closely related to the above topics could be considered by the editors. The detailed information of the journal is available at the website. Proceedings of scientific meetings and conference reports will be considered for special issues.

\section{Submission of Manuscripts}

All manuscripts written in English should be submitted as MS-Word file attachments via e-mail to editoffice@agriscitech.eu. Manuscripts must be prepared strictly in accordance with the detailed instructions for authors at the website

www.agriscitech.eu and the instructions on the last page of the journal. For each manuscript the signatures of all authors are needed confirming their consent to publish it and to nominate on author for correspondence.

They have to be presented by a submission letter signed by all authors. The form of the submission letter is available upon from request from the Technical Assistance or could be downloaded from the website of the journal. Manuscripts submitted to this journal are considered if they have submitted only to it, they have not been published already, nor are they under consideration for publication in press elsewhere. All manuscripts are subject to editorial review and the editors reserve the right to improve style and return the paper for rewriting to the authors, if necessary. The editorial board reserves rights to reject manuscripts based on priorities and space availability in the journal.

The journal is committed to respect high standards of ethics in the editing and reviewing process and malpractice statement. Commitments of authors related to authorship are also very important for a high standard of ethics and publishing. We follow closely the Committee on Publication Ethics (COPE), http://publicationethics.org/resources/guid $\underline{\text { elines }}$

The articles appearing in this journal are indexed and abstracted in: DOI, EBSCO Publishing Inc. and AGRIS (FAO).

The journal is accepted to be indexed with the support of a project № BG051P00013.3.05-0001 "Science and business" financed by Operational Programme "Human Resources Development" of EU. The title has been suggested to be included in SCOPUS (Elsevier) and Electronic Journals Submission Form (Thomson Reuters).

\section{Address of Editorial office:}

Agricultural Science and Technology Faculty of Agriculture, Trakia University Student's campus, 6000 Stara Zagora Bulgaria

Telephone.: +35942699330 $+35942699446$

www.agriscitech.eu

\section{Technical Assistance:}

Nely Tsvetanova

Telephone.: +35942699446

E-mail: editoffice@agriscitech.eu 


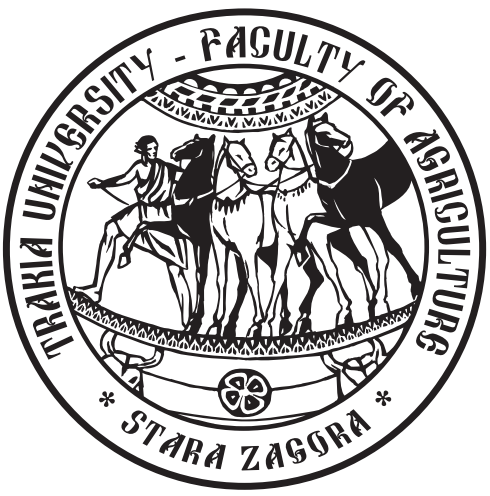

AGRICULTURAL

SCIENCE AND TECHNOLOGY

\section{6}

An International Journal Published by Faculty of Agriculture,

Trakia University, Stara Zagora, Bulgaria 


\title{
Effect of fluorescence on the technological characteristics of cocoons at different cooking temperatures
}

\author{
M. Panayotov* \\ Department of Animal science-Non-ruminant and other animals, Faculty of Agriculture, Trakia Univercity, 6000, Stara Zagora, Bulgaria
}

(Manuscript received 5 May 2016; accepted for publication 11 August 2016)

\begin{abstract}
The subject of research are Bombyx mori L. cocoons, differentiated by the nature of their fluorescent radiation. In each fluorescent group 2 subgroups were formed prepared for unreeling through cooking at 80 and $90^{\circ} \mathrm{C}$ for $5 \mathrm{~min}$. To account for the effect of fluorescence at various cooking temperature levels the basic technological traits signs of the silk filament and cocoons have been defined and analysed: total length of the silk filament ( $m$ ), nonbroken filament length $(\mathrm{m}, \%)$, raw silk pesentage $(\%)$ and reelability $(\%)$. It was found that fluorescence of cocoons has statistically significant ( $p \leqslant 0.01-$ 0.001) effect on the phenotypic manifestation of the technological traits. Within the two cooking temperature levels, the yellow fluorescent cocoons demonstrate higher values at $80^{\circ} \mathrm{C}$, and violet ones at $90^{\circ} \mathrm{C}$. The better technological qualities and the lower cooking temperature in the yellow fluorescent cocoons give reason to believe that their use is economically more profitable for the silk reeling industry compared with violet fluorescent cocoons.
\end{abstract}

Keywords: Bombyx mori, fluorescence, temperature, cooking

\section{Introduction}

The main parameters defining the physico-mechanical and technological properties of the silk filament depend primarily on preserving the natural qualities of the silk sheath in the process of preliminary preparation and drawing of cocoons. The existing technologies for processing cocoons into silk are based on the ability of sericin to swell and dissolve in water. Crucial for the effectiveness of the unreeling process incl. silk quality is the extent, dissolution time of sericin and the factors influencing them. The conditions of cocoon brewing affect significantly the process of water absorption by the silk shell and cocoon, which reflects on the effect of drawing (Naik etal., 2010).

Cocoon quality affects the productivity of the unreeling process and the quality of raw silk. Which in turn depends on the hybrid, technologies of cultivation and processing of cocoons (Somashekar, 2003). The interaction between the factors breed affiliation of cocoons and conditions for their unreeling affects the physical and mechanical properties of raw silk (Radhalakshmi et al., 2013; Bandyopadhyay et al., 2014).

One of the main factors influencing the properties and behavior of sericin during the unreeling process is the temperature at which it is carried out. The effect of temperature depends on both its values and the duration of the processes (Hu and Kobayashi, 1992; Takabayashi et al., 1998; Hariraj and Somshekar, 2004; Mwasiagi et al., 2012). According to Takasu et al. (2002) the high temperature and its prolonged impact destroy the sericin molecules. At elevated temperatures from 40 to $80^{\circ} \mathrm{C}$, the dissolution of sericin initially decreases, then increases to reach $100 \%$ at $80^{\circ} \mathrm{C}$. The low and high cooking temperature cause uneven dissolution of sericin.

To achieve optimum results in unreeling it is necessary sericin swelling to reach a certain degree. This makes the continuous cooking of cocoons at high temperature economically inefficient for the unreeling process. Both overexposure and insufficient cooking of cocoons has a negative impact on the quality of the silk filament and raw silk yield at the expense of more waste products (Kar et al., 2016).

The optimum temperature for the preparation of cocoons depends on their quality. Ramesh et al. (2005) tested the effect of two levels of cooking $\left(86\right.$ and $90^{\circ} \mathrm{C}$ ) on some technological parameters of normal and defective cocoons. The highest values in normal cocoons by mass of the silk skein, total and continuous unreeling length, the lowest average number of breaking and the lowest percentage of waste products from drawing have been obtained from normal cocoons cooking at $86^{\circ} \mathrm{C}$, followed by those cooking at $90^{\circ} \mathrm{C}$. As a result of the conducted study the conclusion is that the most suitable temperature for reeling normal cocoons is $86^{\circ} \mathrm{C}$, and for the defective ones $-90^{\circ} \mathrm{C}$.

Kinoshita et al. (1980) and Shimazaki (1983) considered it necessary to standardize the conditions for the preparation of cocoon cooking depending on their qualities. Standardization and improvement of conditions leads to lower prime cost of the raw silk. The need for differentiation of the conditions under which the optimal reeling preparation process takes place (temperature, duration, pressure) is accounted for by the different solubility of sericin in the shells of different hybrids. Kar et al. (2016) also believe that by manipulating the set of conditions for reeling cocoons the quantitative and qualitative results of the unreeling process can be improved. As an alternative, they propose replacing the traditional method of cooking for 3 min and drawing at $100^{\circ} \mathrm{C}$ by brewing under vacuum for $2-3 \mathrm{~min}$ and drawing at $50-60^{\circ} \mathrm{C}$. An effective means for manipulating the conditions of unreeling is brewing of cocoons in strongly alkaline water with $\mathrm{Ph} 11.50$ at temperature of $70^{\circ} \mathrm{C}$ for 15 min and obtaining the same or better results compared to the conventional conditions (Cao et al., 2014).

The review of available literature shows that for optimizing the conditions of cocoon preparation for reeling and enhancing the economic efficiency of the reeling process it is necessary to develop

*e-mail: panayotov_m@abv.bg 
and implement different treatment based on criteria that objectively reflect their technological properties.

In this regard, we aim to determine the effect of fluorescence on the phenotypic expression of major technological characteristics in Bombyn mori L. cocoons, depending on the cooking temperatures.

\section{Material and methods}

This study was conducted in the period $2014-2015$ at the Training experimental base of "Silk-worm breeding"section at the Faculty of Agriculture, Trakia University, Stara Zagora.

The material used comprised top quality cocoons of the tetrahybrid $(19 \times 1013) \times(20 \times 1014)$. The latter has been created at the base of the section by crossing populations of univoltine breeds of Bombyx mori L. The cocoons produced from the hybrid cocoons were divided into three factions - with yellow, intermediate and violet fluorescence. For this purpose we used a quartz lamp with a filter permeable to ultraviolet rays within the range of $330-400 \mathrm{~nm}$. The preparation of cocoons for reeling was conducted in two temperature modes -80 and $90^{\circ} \mathrm{C}$ with duration of $5 \mathrm{~min}$. For this purpose in each fluorescent fraction we formed two subsets. The reeling of cocoons from all subsets was made in distilled water at $60^{\circ} \mathrm{C}$. To account for the impact of various cooking modes, using standard methods in sericulture, we identified and analyzed the key technological features of cocoons and silk filaments. The primary information needed to identify them was obtained by individual reeling of cocoons and weighing the components extracted from them and dried to constant weight by using electronic scales (KERN PCB250-3) with an accuracy of $0.001 \mathrm{~g}$.

By analysis of variance (ANOVA) for each model were derived by classes of fixed factors the least square mean (LSM) and least square estimate (LSE), representing sums of squares calculated as deviation from the mean value of the parameter derived from the model.

\section{Results and discussion}

Table 1 presents the results of analysis of variances for the effect of fluorescence on the phenotypic manifestation of technological traits of cocoons and silk filament: total length of silk filament $(m)$, nonbroken filament length $(m, \%)$, reelability $(\%)$ and raw silk percentage. It is obvious that the factor fluorescence has a statistically significant impact on the controlled technological traits $(p \leqslant 0.01-0.001)$.

The longest silk filament $(1165 \mathrm{~m})$ has been drawn from cocoons with yellow fluorescence at cooking temperature of $80^{\circ} \mathrm{C}$ and the shortest in cocoons with intermediate one $(1034 \mathrm{~m})$ at $90^{\circ} \mathrm{C}$ (Table 2).
The analysis of the data in the table indicates that cooking temperature affects differently the total length of silk filament drawn from cocoons with different fluorescence. The increase of temperature from 80 to $90^{\circ} \mathrm{C}$ is followed by a decrease in the values of the trait by 39 and $66 \mathrm{~m}$, respectively, for the intermediate and yellow fluorescent cocoons and increase by $42 \mathrm{~m}$ for the violet fluorescent ones. It is evident from the stated data that the most significant change occurs in cocoons with yellow fluorescence $(6 \%)$. In support of the findings made are the Ls-estimates of the analysed fluorescent groups, depending on the temperature regime. It is evident that the factors fluorescence and temperature affect both the extent and the nature of differences compared to the average for the model. At $80^{\circ} \mathrm{C}$ the violet and intermediate fluorescent groups have silk filament 38 and $21 \mathrm{~m}$ shorter than the average for the model, while the yellow ones - $71 \mathrm{~m}$ longer. By increasing temperature to $90^{\circ} \mathrm{C}$, change occurs only in the violet group, which from lower at $80^{\circ} \mathrm{C}$ demonstrated albeit slightly higher than the average value for the model. In the other two groups the type is preserved, but the level of difference compared to the average for the model changes. In the intermediate group the difference increases from -21 to $-60 \mathrm{~m}$, while in the violet one it declines from +71 to +5 meters. The combined analysis of the data in Table 2 shows that for the yellow fluorescent cocoons more effective is cooking of cocoons before drawing at 80 , while for the violet fluorescent ones at $90^{\circ} \mathrm{C}$.

Ls-means and Ls-estimates about the effect of fluorescence on the nonbroken filament length in $\mathrm{m}$ and in $\%$ of the total unreeling length are presented in Table 3. The highest mean values in both temperature modes have cocoons with yellow fluorescence (1037 $\mathrm{m})$, and the lowest ones - those with violet at cooking mode $80^{\circ} \mathrm{C}$ $(835 \mathrm{~m})$. The increase of temperature results in an improvement of the trait values in the cocoons with violet and yellow fluorescence. This is better manifested in the violet fluorescent ones, the mean values of which are $117 \mathrm{~m}$ less at $80^{\circ} \mathrm{C}$ and $4 \mathrm{~m}$ more than the average for the model. With increase of temperature the yellow fluorescent cocoons improve their characteristics by $25 \mathrm{~m}$, while the intermediate ones deteriorate it by $40 \mathrm{~m}$ compared to the average for the model.

The mean values and estimates presented in Table 3 show that in both modes with the highest \% compared to the total silk filament length are cocoons of the yellow, followed by the intermediate and the lowest ones are those of the violet fluorescent group. Increase of temperature results in decrease of the average percentage of the nonbroken silk filament by 5.74 and $1.38 \%$ in the intermediate and yellow fluorescent groups and increase in the violet one by $13.7 \%$. Ununiform effect of the temperature mode on the percentage of nonbroken length of the silk filament depending on fluorescence is confirmed by the changes in Ls-estimates, too. In the intermediate and yellow fluorescent groups, the increase of temperature deteriorates the values of the trait by 5.74 and $1.35 \%$, respectively. An opposite trend is observed in the violet group. In it, increase of

Table 1. Analysis of variance of effects of fluorescence on studied technological traits

\begin{tabular}{lccc}
\hline \hline Sources of variation & Degrees of freedom $(\mathrm{n}-1)$ & $\mathrm{F}$ & $\mathrm{P}$ \\
\hline Total filament length $(\mathrm{m})$ & 2 & 9.01 & $* * *$ \\
Nonbroken filament length $(\mathrm{m})$ & 2 & 5.32 & $* *$ \\
Nonbroken filament length $(\%)$ & 2 & 13.08 & $* * *$ \\
Reelability (\%) & 2 & 23.4 & $* * *$ \\
Raw silk percentage $(\%)$ & 2 & 12.07 & $* * *$ \\
\hline \hline
\end{tabular}

NS: **: $\mathrm{P}<0.01 ; * * *: \mathrm{P}<0.001$ 
Table 2. LS- mean and LS- estimate for influence of the fluorescence on the total filament length $(\mathrm{m})$ at different temperatures of cooking

\begin{tabular}{|c|c|c|c|}
\hline Source of variation & $n$ & LS-mean $\pm S E$ & LS-estimate \\
\hline Mean of the model & 264 & $1094 \pm 8.81$ & \\
\hline \multicolumn{4}{|l|}{$80^{\circ} \mathrm{C}$} \\
\hline violet & 56 & $1056 \pm 28.53$ & -38 \\
\hline intermediate & 30 & $1073 \pm 21.93$ & -21 \\
\hline yellow & 46 & $1165 \pm 14.34$ & +71 \\
\hline \multicolumn{4}{|l|}{$90^{\circ} \mathrm{C}$} \\
\hline violet & 45 & $1098 \pm 23.98$ & +4 \\
\hline intermediate & 39 & $1034 \pm 14.66$ & -60 \\
\hline yellow & 48 & $1099 \pm 22.24$ & +5 \\
\hline
\end{tabular}

temperature results in improvement of the trait values. Despite the fact that they are lower than the average for the model, the difference of $-14.9 \%$ reduced to $-1.28 \%$. According to Takabayashi et al. (1996), the conditions of preparation of cocoons influence the process of drawing the silk filament by changes in the binding forces between the filament and the silk sheath as a whole. Optimizing the conditions in the preparation of cocoons reduces resistance and breaking of the silk filament. The values about the continuous unreeling length in $\mathrm{m}$ and $\%$ give us reason to assume that the swelling of sericin and reducing the resistance forces in the yellow fluorescent cocoons is achieved at lower $\left(80^{\circ} \mathrm{C}\right)$ cooking temperature, and for the violet-fluorescent ones $-90^{\circ} \mathrm{C}$.

The highest reelability rate $(89.12 \%)$ is exhibited by cocoons with yellow fluorescent characteristics at mode of $80^{\circ} \mathrm{C}$, and the lowest one (85.24) with violet at the same temperature mode (Table 4). The data from the table show that the change in temperature mode has an ununiform effect on the phenotypic manifestation of the unreeling trait depending on the fluorescent characteristics of silk sheaths. Intermediate and yellow fluorescent ones deteriorate their reeling qualities by 2.75 and $0.64 \%$, respectively, by increasing temperature from 80 to $90{ }^{\circ} \mathrm{C}$, more pronounced, as evidenced in the group with intermediate fluorescence. Unlike the above groups, the higher temperature improved by $2.59 \%$ the reeling qualities of cocoons with violet fluorescence. The reported impact of the temperature mode depending on fluorescence is confirmed by the comparison between the average unreeling rate values of the fluorescent groups and the average for the model.

The reeling capacity of the silk sheath affects directly the weight characteristics of components the ration of which determines one of the basic technological features, with major contribution to the economic efficiency of the unreeling process. This explains the uniformity of the results reported above with the data about the raw silk percentage.

The highest production of raw silk $(42.58 \%)$ have the yellow fluorescent cocoon mode at mode of $80^{\circ} \mathrm{C}$, and the lowest, the

Table 3. LS- mean and LS - estimate for influence of the fluorescence on the nonbroken filament length at different temperatures of cooking

\begin{tabular}{|c|c|c|c|c|c|}
\hline \multirow{2}{*}{ Source of variation } & \multirow{2}{*}{$\mathrm{n}$} & \multicolumn{2}{|c|}{ Nonbroken filament length, $\mathrm{m}$} & \multicolumn{2}{|c|}{ Nonbroken filament length, \% } \\
\hline & & LS-mean \pm SE & LS-estimate & LS-mean $\pm S E$ & LS-estimate \\
\hline Mean of the model & 264 & $952 \pm 17.09$ & & $87.44 \pm 1.44$ & \\
\hline \multicolumn{6}{|l|}{$80^{\circ} \mathrm{C}$} \\
\hline violet & 56 & $835 \pm 38.97$ & -117 & $72.46 \pm 3.55$ & -14.98 \\
\hline intermediate & 30 & $996 \pm 39.32$ & +44 & $93.39 \pm 3.20$ & +5.95 \\
\hline yellow & 46 & $1012 \pm 25.56$ & +60 & $96.17 \pm 1.00$ & +8.73 \\
\hline \multicolumn{6}{|l|}{$90^{\circ} \mathrm{C}$} \\
\hline violet & 45 & $956 \pm 49.07$ & +4 & $86.16 \pm 3.55$ & -1.28 \\
\hline intermediate & 39 & $912 \pm 47.27$ & -40 & $87.65 \pm 4.29$ & +0.21 \\
\hline yellow & 48 & $1037 \pm 32.51$ & +85 & $94.79 \pm 2.37$ & +7.35 \\
\hline
\end{tabular}

Table 4. LS- mean and LS- estimate for influence of the fluorescence on the raw silk percentage and reelability (\%) at different temperatures of cooking

\begin{tabular}{|c|c|c|c|c|c|}
\hline \multirow{2}{*}{ Source of variation } & \multirow{2}{*}{$n$} & \multicolumn{2}{|c|}{ Reliability, \% } & \multicolumn{2}{|c|}{ Raw silk percentage, $\%$} \\
\hline & & LS-mean \pm SE & LS-estimate & LS-mean $\pm S E$ & LS-estimate \\
\hline Mean of the model & 264 & $87.53 \pm 0.28$ & & $40.70 \pm 0.28$ & \\
\hline \multicolumn{6}{|l|}{$80^{\circ} \mathrm{C}$} \\
\hline violet & 56 & $85.24 \pm 0.55$ & -2.29 & $39.37 \pm 0.76$ & -1.33 \\
\hline intermediate & 30 & $88.77 \pm 0.62$ & +1.24 & $40.33 \pm 0.64$ & -0.37 \\
\hline yellow & 46 & $89.12 \pm 0.56$ & +1.59 & $42.58 \pm 0.50$ & +1.88 \\
\hline \multicolumn{6}{|l|}{$90^{\circ} \mathrm{C}$} \\
\hline violet & 45 & $87.83 \pm 0.69$ & +0.3 & $40.96 \pm 0.66$ & +0.26 \\
\hline intermediate & 39 & $84.02 \pm 0.73$ & -3.51 & $38.37 \pm 0.86$ & -2.33 \\
\hline yellow & 48 & $88.48 \pm 0.60$ & +0.95 & $41.80 \pm 0.53$ & +1.1 \\
\hline
\end{tabular}


intermediate fluorescent ones at $90^{\circ} \mathrm{C}$ (Table 3). The increase of temperature results in decrease of yield of the above groups by 0.78 and $1.96 \%$, respectively, and increase in the violet one by $1.59 \%$. Cocoons with yellow fluorescence are characterized by the highest Ls-estimates. They exceed the average yield for the model by 1.24 and $0.3 \%$, respectively, at 80 and $90^{\circ} \mathrm{C}$.

The Ls-estimates presented in Table 4 show that in mode $80^{\circ} \mathrm{C}$, the yield from violet fluorescent cocoons is $1.33 \%$ lower, while in mode $90^{\circ} \mathrm{C}$ is $0.26 \%$ higher than the average for the model (40.70\%). The results in Table 4 show that the two end fluorescent fractions differ in temperature modes, determining higher degree of phenotype manifestation of the traits analyzed in the table. Higher values of cocoons with yellow fluorescence produced at a lower cooking temperature mode compared with violet fluorescent ones can be explained by the lower sericin content in yellow fluorescent cocoons (Panayotov, 2014) and the established relationship between the nature of ultraviolet radiation from cocoons and the behavior of sericin in its dissolution (Aoki et al., 1986; Chang and Nahm, 1988). The higher solubility of sericin from the cocoons with yellow fluorescence is related to the weaker adhesive properties of sericin in them, as compared with the violet fluorescent ones (Ajisava, 1998).

Drawing of cocoons at a lower temperature is important for the fluorescent cocoons, which as a result of the denaturing of the proteins at temperature of $100{ }^{\circ} \mathrm{C}$ lose their fluorescent radiation. In this respect, Park et al. (2013) developed a new method of cooking, wherein the fluorescent cocoons are soaked in a solution of $0.2 \%$ $\left(\mathrm{Na}_{2} \mathrm{CO}_{3}\right)$, and $0.1 \%$ Triton $\mathrm{X} 100$ at $60^{\circ} \mathrm{C}$, then placed under vacuum. The results show that low-temperature processing of cocoons allows to obtain colored fluorescent silk, which does not change its color in the process of drawing.

\section{Conclusion}

The analysis of the data from the present study showed that fluorescence of cocoons has statistically significant $(p \leqslant 0.01-0.001)$ effect on the phenotypic manifestation of the technological traits of cocoons and silk filament: total filament length $(m)$, nonbroken filament $(\mathrm{m}, \%)$, raw silk persentage and reelability). Cocoons differentiated by the nature of the fluorescent radiation react differently to the conditions under which the cooking process is performed $\left(80\right.$ and $90^{\circ} \mathrm{C}$ ) prior to their unreeling. In general, yellow fluorescent cocoons demonstrate higher values in the analysed traits at $80^{\circ} \mathrm{C}$, and violet ones at $90^{\circ} \mathrm{C}$. Having in mind that the optimum level of brewing cocoons is determined by the results of unreeling (Lee, 1999), it can be said that for the yellow fluorescent cocoons lower temperature is needed for preparing the cocoons for unreeling and for the violet ones - higher. The better technological qualities and the lower cooking temperature in the yellow fluorescent cocoons give reason to believe that their use is economically more profitable for the silk reeling industry compared with violet fluorescent cocoons.

\section{References}

Aoki A, Imai T and Kataoka K, 1986. Fluorescence and solubility of sericin for cocoon, raw silk and fabric, produced by the silkworm, Bombyx mori, reared on artificial diet. Technical Reports of
Sericultural Experimental Station, 128, 125-153.

Ajisawa A, 1998. Solubility of fluorescent cocoons. The Journal of Sricultural Sciences of Japan, 67, 95-99.

Bandyopadhyay S, Kar NB and Biswas A, 2014. An Experimental Study on Reeling of Mulberry Silk Yarn. American International Journal of Research in Science, Technology, Engineering \& Mathematics, 8, September-November, 112-116.

Chang SJ and Nahm JH, 1988. Dissolution behavior of sericin in cocoon shell on the fluorescence colours. Korean Journal of Sericultural Science, 30, 65-74.

Cao TT, Wang YJ and Zhang YQ, 2014. Silk reeling of silkworm cocoon in strongly alkaline electrolyzed water as a sericin swelling agent at low temperature. The Journal of The Textile Institute, 105.

Hariraj G and Somashekar TH, 2004. Influence of cooking and adjustment treatments on reeling and quality characteristics of raw silk. Indian Journal of Fibers Textile Research, 29, 207-217.

Hu W and Kobayashi M, 1992. Effect of the spinning environment on dissolution of cocoon shell sericin. Journal of Sericultural Science of Japan, 61, 272-274.

Kinoshita K, Watese H and Sugenuma Y, 1980. Studies on the systematization of cocoon cooking. II: On the optimization of cocoon cooking by temperature patterns, 49, 352-358.

Kar NB, Majumdar MK and Trivedy K, 2016. Effect of Pressurized Cooking \& Low-Temperature Reeling of Cocoon on Qualitative \& Quantitative Traits of Bivoltine Raw Silk. American International Journal of Research in Formal, Applied \& Natural Sciences, 13, 28 32.

Lee YW, 1999. Silk Reeling and Testing Manual. FAO Agricultural Services Bulletin, 136, pp 130.

Mwasiagi JI, Ochola JR, Wambua IM, Musembi AW and Lusweti JK, 2012. Use of Regression models to studi Silk Reeling. International Journal of Engineering Research in Africa, 7, 35-40.

Naik SV, Naik PY, Naik H, Mahadevian BM and Venu ST, 2010. Effect of cocoon cooking conditions on reeling performance and quality characteristics of raw silk of indian bivoltine hybrid cocoons. Sericologia, 50, 255-272.

Park J, Kim S, Jeong Y, Lee J, Go Y, Lee S, Choi K, Kim SR and Go TW, 2013. Reeling of recombinant flourescence cocoons through low temperature decompressed cooking. Journal of Sericultural and Entomological Science, 51, 142-146.

Panayotov M, 2014. Sericin content in haq silk from Bombyx mori L. Cocoons with different fluorescent characteristics. Agricultural Science and Technology, 6, 395-399.

Ramesh KV, Nageshchandra BK, Sanappa B, Gowda RGS and Govindan R, 2005. Influence of Cooking Temperature on Reeling Characteristics of Normal and effective Mulberry Silk Cocoons Reeled on Multi-End Reeling Machine, Karnataka. Journal of Agricultural Sciences, 18, 515-519.

Radhalakshmi YC, Reshma BS, Kariyappa, Shivakumar KP and Kumar SN, 2013. Studies on the impact of kinetics of cocoon cooking on reeling performance and quality of raw silk. Indian Journal of Sericulture, 52, 71-78.

Shimazaki A, 1983. Subject task force of future reeling technology. Filature and silk conference report, 36-62.

Somashekar TH, 2003. Influence of cocoon racial characteristics on reeling performance and yarn characteristics. In concept papers, Silkworm breeders summit-2003 July 18-19, atAPSSRDI, Hindupur, 86-89.

Takabayashi C, Naik SV and Tsuboi H, 1996. Influence of cocoon cooking conditions on variation of cocoon filament exfoliation tension. Journal Sericology Science Japan, 65, 278-285. 
Takabayashi C, Takasu Y, Nakajima K, Itsubo T, Miyajima T and E Miyazaki, 1998. Cocoon cooking conditions and reeling performance of the characteristic silkworm race's cocoons. Bulletin of the National Institute of Seriluture and Entomology Science, 20,
79-100.

TakasuY, Yamada H and Tsuboushy K , 2002. Extraction and Chromatographic Analysis of Cocoon Sericin of Silkworm, Bombyx mori. Journal of Insect Biotechnology and Sericology, 71,151-156. 
Review

Triticale-past and future

St. Dobreva

\section{Genetics and Breeding}

Productivity performance of bread winter wheat genotypes with local and foreign origin

G. Raykov, P. Chamurliyski, S. Doneva, E. Penchev, N. Tsenov

Production properties of flax (Linum usitatissimum L.) cultivated in Strumica region, Republic of Macedonia

P. Vuckov, M. llievski, D. Spasova, L. Mihajlov, N. Markova-Ruzdić

Quality of grain and flour of foreign bread wheat cultivars (Triticum aestivum L.) under the conditions of south Dobrudzha region

P. Chamurliyski, N. Tsenov, I. Stoeva, S. Doneva, E. Penchev

Breeding programme for developing new sweet cherry cultivars in the Fruit Growing Institute,

Plovdiv, Bulgaria

S. Malchev, A. Zhivondov

Heterosis manifestations by survival and larval duration of F1 Bombyx mori L. hybrids

R. Guncheva, M. Panayotov, P. Tsenov, Y. Dimitrova

\section{Nutrition and Physiology}

Reproductive performance of breeding rabbits fed by graded levels of cassava (Manihot esculenta) leaf meal

T. Ahemen, I.I. Bitto, O.I.A. Oluremi

Clinical toxicological investigations on acute carbofuran intoxication in quails (Coturnix coturnix)

R. Binev, I. Valchev, R. Mihaylov, Y. Nlkolov

\section{Production Systems}

Efficacy and timing of some new products against pear psylla (Cacopsylla pyri L.) (Hemiptera:

Psyllidae): II. Spirodiclofen

V. Arnaudov

Biochemical and chemical investigations of pikeperch fingerlings (Sander Lucioperca L.) after wintering
A. Ivanova, R. Atanasova 
Effect of fluorescence on the technological characteristics of cocoons at different cooking temperatures

M. Panayotov

Comparative analysis of plane geometric parameters of various types of cow milking parlors

D. Georgiev

Agriculture and Environment

Panthaleus major/Duges/ of cereals in Bulgaria

V. Maneva, D. Atanasova

Selectivity and stability of herbicides and their tank mixtures for the seed yield of sunflower (Helianthus Annuus L.)

G. Delchev, T. Barakova

Effect of green manure cover crops on tomato greenhouse production

I. Tringovska, V. Yankova, D. Markova

Reclamation of lands disturbed by mining activities in Bulgaria

I. Kirilov, M. Banov

Product Quality and Safety

Fish production and meat quality traits in rainbow trout (Oncorhynchus mykiss) farmed in different production systems

St. Stoyanova, Y. Staykov, G. Zelqzkov, I. Sirakov, G. Nikolov 


\section{Instruction for authors}

\section{Preparation of papers}

Papers shall be submitted at the editorial office typed on standard typing pages (A4, 30 lines per page, 62 characters per line). The editors recommend up to 15 pages for full research paper ( including abstract references, tables, figures and other appendices)

The manuscript should be structured as follows: Title, Names of authors and affiliation address, Abstract, List of keywords, Introduction, Material and methods, Results, Discussion, Conclusion, Acknowledgements (if any), References, Tables, Figures.

The title needs to be as concise and informative about the nature of research. It should be written with small letter /bold, 14/ without any abbreviations.

Names and affiliation of authors The names of the authors should be presented from the initials of first names followed by the family names. The complete address and name of the institution should be stated next. The affiliation of authors are designated by different signs. For the author who is going to be corresponding by the editorial board and readers, an E-mail address and telephone number should be presented as footnote on the first page. Corresponding author is indicated with *.

Abstract should be not more than 350 words. It should be clearly stated what new findings have been made in the course of research. Abbreviations and references to authors are inadmissible in the summary. It should be understandable without having read the paper and should be in one paragraph.

Keywords: Up to maximum of 5 keywords should be selected not repeating the title but giving the essence of study.

The introduction must answer the following questions: What is known and what is new on the studied issue? What necessitated the research problem, described in the paper? What is your hypothesis and goal?

Material and methods: The objects of research, organization of experiments, chemical analyses, statistical and other methods and conditions applied for the experiments should be described in detail. A criterion of sufficient information is to be possible for others to repeat the experiment in order to verify results.

Results are presented in understandable tables and figures, accompanied by the statistical parameters needed for the evaluation. Data from tables and figures should not be repeated in the text. Tables should be as simple and as few as possible. Each table should have its own explanatory title and to be typed on a separate page. They should be outside the main body of the text and an indication should be given where it should be inserted.

Figures should be sharp with good contrast and rendition. Graphic materials should be preferred. Photographs to be appropriate for printing. Illustrations are supplied in colour as an exception after special agreement with the editorial board and possible payment of extra costs. The figures are to be each in a single file and their location should be given within the text.

Discussion: The objective of this section is to indicate the scientific significance of the study. By comparing the results and conclusions of other scientists the contribution of the study for expanding or modifying existing knowledge is pointed out clearly and convincingly to the reader. Conclusion: The most important consequences for the science and practice resulting from the conducted research should be summarized in a few sentences. The conclusions shouldn't be numbered and no new paragraphs be used. Contributions are the core of conclusions. References:

In the text, references should be cited as follows: single author: Sandberg (2002); two authors: Andersson and Georges (2004); more than two authors: Andersson et al.(2003). When several references are cited simultaneously, they should be ranked by chronological order e.g.: (Sandberg, 2002; Andersson et al., 2003; Andersson and Georges, 2004).

References are arranged alphabetically by the name of the first author. If an author is cited more than once, first his individual publications are given ranked by year, then come publications with one co-author, two co-authors, etc. The names of authors, article and journal titles in the Cyrillic or alphabet different from Latin, should be transliterated into Latin and article titles should be translated into English. The original language of articles and books translated into English is indicated in parenthesis after the bibliographic reference $($ Bulgarian $=\mathrm{Bg}$, Russian $=\mathrm{Ru}$, Serbian $=\mathrm{Sr}$, if in the Cyrillic, Mongolian =
Mo, Greek = Gr, Georgian = Geor., Japanese $=\mathrm{Ja}$, Chinese $=\mathrm{Ch}$, Arabic $=\mathrm{Ar}$, etc.)

The following order in the reference list is recommended:

Journal articles: Author(s) surname and initials, year. Title. Full title of the journal, volume, pages. Example:

Simm G, Lewis RM, Grundy B and Dingwall WS, 2002. Responses to selection for lean growth in sheep. Animal Science, 74, 39-50

Books: Author(s) surname and initials, year. Title. Edition, name of publisher, place of publication. Example:

Oldenbroek JK, 1999. Genebanks and the conservation of farm animal genetic resources, Second edition. DLO Institute for Animal Science and Health, Netherlands.

Book chapter or conference proceedings: Author(s) surname and initials, year. Title. In: Title of the book or of the proceedings followed by the editor(s), volume, pages. Name of publisher, place of publication. Example:

Mauff G, Pulverer G, Operkuch W, Hummel K and Hidden C, 1995. C3variants and diverse phenotypes of unconverted and converted C3. In: Provides of the Biological Fluids (ed. $\mathrm{H}$. Peters), vol. 22, 143-165, Pergamon Press. Oxford, UK.

Todorov N and Mitev J, 1995. Effect of level of feeding during dry period, and body condition score on reproductive performance in dairy cows, $I^{\text {th }}$ International Conference on Production Diseases in Farm Animals, September 11-14, Berlin, Germany.

Thesis:

Hristova D, 2013. Investigation on genetic diversity in local sheep breeds using DNA markers. Thesis for PhD, Trakia University, Stara Zagora, Bulgaria, (Bg).

The Editorial Board of the Journal is not responsible for incorrect quotes of reference sources and the relevant violations of copyrights.

\section{Animal welfare}

Studies performed on experimental animals should be carried out according to internationally recognized guidelines for animal welfare. That should be clearly described in the respective section "Material and methods". 


\section{AGRICULTURAL \\ SCIENCE AND TECHNOLOGY}

Volume 8, Number 4

December 2016
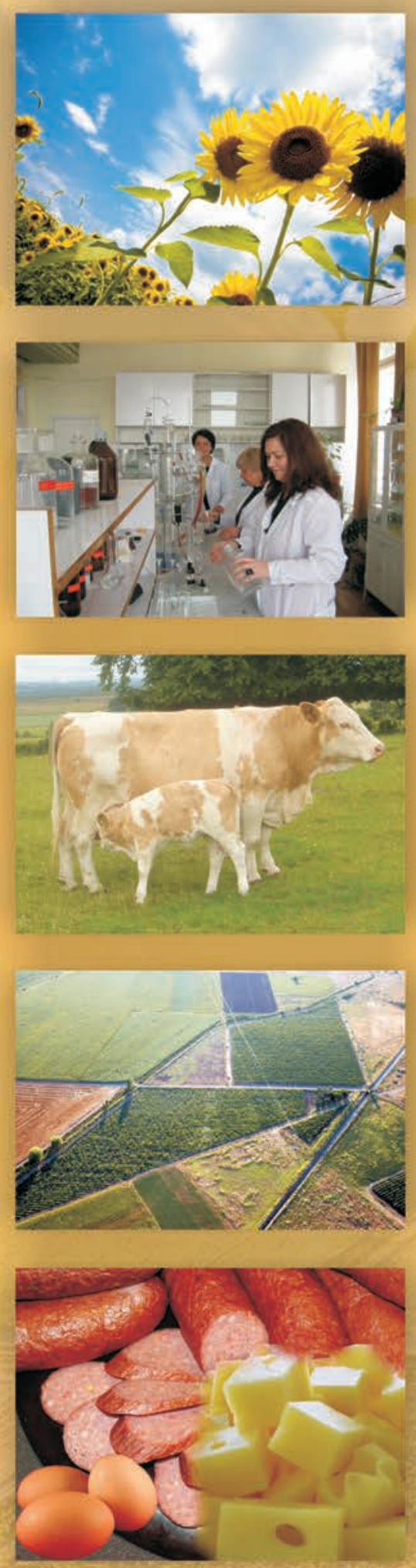

Journal web site: 